\title{
A SAGA DO IDEAL DE BOA CIÊNCIA
}

\section{Renan Springer de Freitas}

O colapso do ideal baconiano de boa ciência, consumado com o advento da teoria da relatividade, o subseqüente insucesso dos empiristas do Círculo de Viena em estabelecer um ideal substituto e a pertinência da crítica de Pierre Duhem ao ideal racionalista levaram a reflexão sobre o que é boa ciência a subordinar-se a uma análise naturalística do processo de aquisição de conhecimento ou, simplesmente, a dissolver-se em uma sociopsicologia do conhecimento. Gostaria de sugerir que nenhuma dessas formas de capitulação é necessária. A reflexão sobre o que é boa ciência, ou, para usar um termo mais familiar, a metodologia, pode reencontrar seu caminho se assumir a posição que, por assim dizer, lhe é de direito: a de carro-chefe da história da ciência. É verdade que há algo de megalomaníaco em supor que a meto-

Artigo recebido em maio/2003

Aprovado em dezembro/2003 dologia possa assumir tão elevada posição, mas não consigo vislumbrar um caminho intermediário entre o recuo a uma das formas de naturalismo a que acabo de fazer menção e uma operação de altíssimo risco. Receio que a metodologia tenha sido conduzida ao fundo de um poço do qual não há mais como sair a não ser dando um salto vertiginoso. O objetivo deste artigo é discutir a viabilidade deste salto.

\section{O ideal de boa ciência na encruzilhada}

O ideal de boa ciência que por mais tempo seduziu a ciência moderna foi, sem dúvida, a concepção indutivista de Francis Bacon. Eu o resumiria assim: boa ciência é a que se mostra capaz de inferir leis naturais a partir do acúmulo de observações. Mais precisamente, é a que dispõe de princípios que, uma vez postos em prática, permi- 
tem que essas leis se mostrem espontaneamente ao intelecto. O princípio fundamental é manter a mente a salvo de enganos. Estes podem vir de toda parte: da imerecida confiança que usualmente depositamos em nossos sentidos, de nossos sentimentos subjetivos, do intercâmbio social e de toda sorte de sistemas, religiosos ou laicos, de pensamento. Se é assim, a condição primordial para a produção de uma boa ciência é a existência de mentes suficientemente bem treinadas para não se deixar enganar por nada disso. Satisfeita esta condição, observações e inferências confiáveis poderão ser feitas, e a produção de uma boa ciência estará garantida. Nada menos que Newton e, posteriormente, Darwin se disseram tributários dessa concepção. Ambos acreditavam, algo ingenuamente, que suas respectivas ciências eram o resultado de um acúmulo criterioso de observações. Na verdade, o ideal baconiano de boa ciência desfrutou de um status canônico por quase três séculos. Com o benefício do olhar retrospectivo, é de espantar que tenha sido preciso que os alicerces da física newtoniana fossem abalados para que ele também se visse abalado. Seja como for, o início do século XX assistiu ao colapso da idéia de que os princípios baconianos garantem uma boa ciência. Isso conduziu a metodologia a um impasse: decidir se a ciência, para merecer este nome, precisa ou não de garantias. Responder que sim demandaria mostrar quais seriam essas garantias. Responder que não demandaria explicar como, na ausência de garantias, a ciência poderia ser uma forma particularmente privilegiada de conhecimento. Os filósofos que, como Carnap e os empiristas lógicos de um modo geral, responderam sim, não foram capazes de mostrar as garantias. Os que, como Popper, responderam não, foram mais bem-sucedidos. Eles foram capazes de conceber uma ciência sem garantias: a ciência, disseram, mesmo não dispondo de um método capaz de assegurar, de antemão, a validade de seus resultados, constitui uma forma privilegiada de conhecimento porque é a única capaz de se expor a testes e de resistir a eles. Com essa resposta, a metodologia pôde sair da encruzilhada a que foi conduzida pela crise da Física do fim do século XIX. Postulou-se, a partir daí, que a qualidade de uma ciência não reside na extensão em que observações e generalizações indutivamente estabelecidas se mostram depuradas das ilusões cognitivas a que a mente humana está inevitavelmente exposta, mas, sim, na diversidade de conseqüências empíricas que podem ser deduzidas de seus enunciados e na capacidade que essas exibem de resistir a testes.

Esse novo ideal de boa ciência, de caráter racionalista, foi plenamente encampado pelos livros-textos de metodologia científica. Tome-se, por exemplo, o notável livro de Stinchcombe, Constructing social theories, de 1968. Ele apresenta a abordagem sociológica de Durkheim sobre o suicídio como um modelo de boa ciência. Com efeito, é difícil imaginar um trabalho - refiro-me, evidentemente, ao clássico O suicídio - em que o ato de derivar conseqüências empíricas de enunciados e submetê-las a testes seja tão ubíquo. A discussão de Durkheim sobre o suicídio no exército merece particular atenção. Sabia-se que os militares se matavam mais do que os civis em qualquer país da Europa. Convencionalmente se pensava que seria por causa das adversidades inerentes à vida militar. Vida militar envolve privação da liberdade, convívio forçado e permanente exposição a toda sorte de humilhações. Tudo isso é verdade, admite Durkheim, mas o suicídio no exército nada tem a ver com isso. O suicídio nesta corporação é da mesma natureza que o suicídio nas sociedades ditas primitivas. Em ambos os casos, uma fatia considerável de autonomia é subtraída dos indivíduos em favor de uma identidade coletiva. No limite, a própria noção de autonomia individual perde sentido. O sentido da vida passa, então, a se localizar fora dela. Daí, o suicídio. Para tornar esta tese empiricamente tratável, Durkheim derivou nada menos que quatro conseqüências empíricas, três das quais extremamente contra-intuitivas, e testou-as uma a uma. Sua tese demandava que os voluntários se matassem mais do que os não voluntários, que os militares mais antigos na corporação se matassem mais do que os mais recentes, que os militares de alta patente se matassem mais do que os de baixa patente e que, em países protestantes, o índice de agravamento do suicídio fosse menor 
que em países católicos. Essas quatro demandas foram satisfeitas.

Igualmente notável foi a forma como Durkheim procedeu para corroborar sua tese fundamental de que a explicação para taxas de suicídio deve ser buscada no exame da natureza dos laços sociais e não em qualquer fator de caráter psicológico. Durkheim propôs que a explicação para, digamos, a taxa comparativamente baixa de suicídios entre os católicos deve ser buscada na natureza dos laços sociais que se estabelecem entre eles e, não, como se tenderia, então, a supor, no fato de o catolicismo ser implacável com o suicida a ponto de negar-lhe um enterro cristão. Uma implicação desta tese é a de que, embora seja verdade que os católicos temam pelo destino de suas almas caso venham a se matar, as baixas taxas de suicídio entre eles nada têm a ver com isto. Para tornar tal afirmação empiricamente tratável, Durkheim voltou-se para os judeus. O judaísmo é relativamente tolerante no que concerne ao suicídio. Um judeu não teme arder no inferno caso se mate. Ademais, há uma clara e sabida conexão entre o suicídio e três fatores: grau de instrução elevado, procedência urbana e dedicação ao comércio. Essa conjunção de fatores (refiro-me aos quatro) faz do judeu um sério candidato ao suicídio. Se, entretanto, o que conta é a natureza dos laços sociais, e os laços entre os judeus são estreitos, então é de se esperar, contra os quatro fatores acima, que os judeus se matem muito pouco. Durkheim procura então mostrar que este é o caso. De um único golpe, a saber, a comparação das taxas de suicídio entre judeus e católicos, ele procurou mostrar a superioridade de sua tese sobre nada menos que quatro teses alternativas. Dada a ousadia de Durkheim em pretender corroborar um enunciado e, ao mesmo tempo, refutar quatro alternativos por meio do simples expediente de derivar do primeiro uma conseqüência empírica cuja negação é demandada por todos os outros, não é de estranhar que O suicídio seja apresentado como um modelo de boa ciência pelos melhores livros-textos de metodologia das ciências sociais.

\section{A espada de Duhem}

Esse ideal racionalista de boa ciência representa, sem dúvida, um avanço desmedido em relação à visão baconiana. Não obstante, já nasceu com uma espada sobre a cabeça. Ele demanda que o falseamento de uma conseqüência empírica seja transferido para o enunciado do qual ela foi deduzida. Tal transferência, entretanto, nem sempre é possível porque, sempre que derivamos uma conseqüência empírica $\mathrm{C}$, de um enunciado $\mathrm{E}$, este último se articula a muitos outros, digamos, $E_{1}, E_{2}$ e $E_{3}$ e, se a primeira é falseada, não podemos saber com certeza se o responsável por isto é E ou qualquer um dos outros enunciados aos quais ele se articulou. Considere-se, por exemplo, o enunciado E: "A Terra é redonda". Derivemos dele a conseqüência empírica C: "quando um navio se dirige para a linha do horizonte, o mastro será a última parte a desaparecer". O simples fato de testar esta conseqüência empírica estabelece uma conexão entre E e todo um conjunto de outros enunciados. Para efeito de exposição, vou me limitar a imaginar três. $E_{1}$ : "aquele objeto, a uns 200 metros de nós, é um navio se dirigindo à linha do horizonte". E2: "os seres humanos são capazes de perceber um navio desaparecendo, aos poucos, no horizonte". E: "nossas percepções são plenamente confiáveis". Suponhamos, agora, que tenhamos observado o navio desaparecer na linha do horizonte e que o mastro não tenha sido a última parte a desaparecer. Que enunciado terá sido falseado nesse caso? Idealmente estamos testando E: "A Terra é redonda". Mas a observação de que o mastro não foi a última parte a desaparecer contraria igualmente a $E_{1}, E_{2}$ e $E_{3}$ ou, mesmo, um En que sequer nos tenha ocorrido. Ela não é, portanto, um meio inequívoco de refutar E. Assim, se derivamos uma conseqüência empírica $\mathrm{C}$ de um enunciado $\mathrm{E}$, e C revela-se falso, idealmente supomos que $\mathrm{E}$ é falso. Mas muitas vezes não podemos saber se a falsidade de $\mathrm{C}$ transfere-se para $\mathrm{E}$ ou para algum outro (ou alguns outros) enunciado(s) a que $\mathrm{E}$ veio a se articular no momento em que $C$ foi submetido a teste. Essa impossibilidade pode manter 
E permanentemente a salvo de refutação, o que seria um golpe mortal para o ideal racionalista de boa ciência.

Pierre Duhem chamou pioneiramente a atenção para esse problema antes mesmo que esse ideal viesse a se estabelecer. Popper, bom leitor de Duhem que era, mostrou-se ciente de tudo isso, mas não pensou que estivesse diante de um problema tão grave (Popper, 1999, pp. 4344). É verdade, ele diz, que muitas vezes não é possível saber que enunciado de um sistema teórico está sendo falseado quando uma conseqüência empírica deste sistema é falseada. Nesses casos, ele prossegue, o cientista deve seguir seus instintos e contar com a sorte (Idem, pp. 80-81). Se não há como afastar a espada, nada mais resta a fazer a não ser torcer para que ela não caia! Mas houve quem não achasse prudente contar com a sorte. Refiro-me a Lakatos.

Lakatos quis manter o novo ideal canônico de boa ciência a salvo das objeções de Duhem propondo o que denominou "metodologia dos programas de pesquisa". Um "programa de pesquisas" é uma série de teorias ancoradas em um conjunto articulado de pressupostos teóricos e metateóricos, cuja validade pode ser, até segunda ordem, presumida (Lakatos, 1970). Para que exista uma série de teorias é necessário que haja uma primeira, da qual se possa derivar uma ou mais conseqüências empíricas. Suponhamos que uma dessas conseqüências seja contrariada pela experiência. Como, nesse caso, identificar a parte da teoria que foi afetada? Não precisamos identificar, responde Lakatos. Podemos, nesse caso, recorrer a uma hipótese auxiliar para manter a teoria a salvo do contra-exemplo. Há, entretanto, algo a exigir dessa hipótese auxiliar: que se mostre capaz de antecipar fatos novos. Na medida em que o faz, converte-se na segunda teoria da série que compõe o programa de pesquisas. Esse processo pode continuar indefinidamente. Mesmo as hipóteses auxiliares que não são bem-sucedidas o suficiente para se elevarem à condição de teoria de um programa de pesquisa cumprem um papel fundamental. Nenhum programa de pesquisa pode prosperar se não for capaz de desenvolver uma heurística que sirva de "cinto de proteção" para seu núcleo básico de pressupostos, e as hipóteses auxiliares são a fonte dessa heurística.

Para ilustrar tudo isso vou me valer da famosa tese de Marx de que a revolução comunista deveria ocorrer na Inglaterra, país cujas "condições materiais" eram, então, as mais maduras para uma ação revolucionária. A revolução comunista, como sabemos, ocorreu na Rússia, país cujas "condições materiais" não eram nada propícias. Isto parece afetar a tese, que faz parte do "núcleo duro" de pressupostos metateóricos do marxismo, de que o "ser social determina a consciência". Uma hipótese auxiliar veio, entretanto, em socorro deste pressuposto. A chamada tese do "elo mais fraco da corrente", de Lênin. De acordo com ela, a Inglaterra e a Rússia não podem ser tomadas como unidades estanques. Ambas constituem elos de uma mesma corrente e, portanto, o que ocorre em um país tem repercussão sobre o outro. Uma vez que esta tese encerra a regra "não se deve tomar fronteiras nacionais como unidades auto-contidas de análise sociopolítica", a qual passou a fazer parte da heurística marxista, ela torna o enunciado "A revolução comunista deve ocorrer na Inglaterra" imune ao fato de a revolução ter ocorrido na Rússia porque o vincula ao enunciado "Inglaterra e Rússia são elos de uma mesma corrente". Mas, vale isso? Sim, responde Lakatos, desde que a teoria do elo mais fraco da corrente se mostre capaz de antecipar fatos novos. Ela antecipa, por exemplo, a revolução chinesa e/ou a cubana? Se sim, estamos diante de uma boa ciência. Se não, não estamos. Há, entretanto, um problema, para o qual Feyerabend (1977) chamou devidamente a atenção. Lakatos quer relaxar os critérios popperianos de boa ciência sugerindo que se dê uma chance às teorias cujas conseqüências empíricas foram falseadas. Mas por que não duas, ou três? Afinal, teorias não são como namorados mal-comportados que só merecem uma única chance. Lakatos, certamente, teria de admitir isto, o que, no limite, conduziria a uma completa imunização da teoria contra o falseamento. Seria a espada de Duhem de volta ao cenário. 


\section{O ideal de boa ciência se rende ao naturalismo}

Antes que Lakatos pudesse, bem ou mal, se haver com a advertência de Duhem, houve quem se valesse dela para colocar em cheque a própria pertinência de uma reflexão apriorística sobre o que é uma boa ciência. Refiro-me, agora, a Quine. De acordo com ele, se alguma reflexão metodológica (isto é, sobre o que é uma boa ciência) é, de todo, possível, esta não pode ter um caráter apriorístico. Ela deve estar subordinada a uma investigação sobre como o conhecimento é efetivamente adquirido - sobre como, a partir de tão pouco: as estimulações sensoriais, que é tudo o que nos é imediatamente dado, podemos produzir algo tão magnífico quanto, por exemplo, as teorias científicas. Inaugurou-se, assim, o que veio a ser conhecido como a abordagem naturalista do conhecimento. A reflexão metodológica passou, a partir daí, a ser vista como um dos possíveis subprodutos de uma análise sobre o modo como se dá a aquisição de conhecimento.

Para analisar esse processo, Quine tomou o aprendizado de uma língua como modelo. Grosso modo, ele diz, este aprendizado se dá por duas vias. A primeira, mais primitiva, é a da ostensão. Esta se verifica quando um adulto aponta um objeto para uma criança (ou um nativo aponta um objeto para um estrangeiro) e diz o nome desse objeto. Após algumas indicações, a criança (ou o estrangeiro) saberá associar palavras como "pássaro", "camisa", "meia" etc., aos objetos correspondentes. A segunda é, entretanto, a que mais interessa no que concerne a seu argumento. Trata-se, agora, do processo de aprender a associar palavras e sentenças não a objetos, mas umas às outras, em níveis crescentes de autonomia em relação à experiência sensível. Assim, aquilo que, no plano primitivo da ostensão pode ser, na melhor das hipóteses, descritível como, digamos, "pássaro", num plano mais complexo pode se traduzir em "eis um pássaro batendo as asas", "o pobre animal está assustado" e, num plano ainda mais complexo, "há transformação de energia nesse local".

Compreender a ciência, sugere Quine, não é diferente de compreender como um estímulo tão primitivo como o espetáculo de um pássaro agitando as asas pode acabar por conduzir a uma resposta tão formidável quanto o enunciado "há transformação de energia nesse local". Como um salto como este pode ser dado? Só pode haver uma explicação, raciocina Quine: entre o estímulo sensorial e a resposta formidável deve haver uma miríade de outros enunciados, alguns mais próximos do estímulo, outros da resposta, os quais são formados à medida que uma resposta ao estímulo original serve de estímulo para uma resposta de nível um pouco mais complexo, e assim sucessivamente, até que um enunciado como "há transformação de energia nesse local" possa ser produzido. Nessa perspectiva, a ciência tem um caráter necessariamente holístico. Ela consiste de redes inteiras de enunciados que só fazem sentido em bloco. A principal lição metodológica que Quine tira daí é a de que, ao contrário de tudo o que os livros-textos de metodologia científica apregoam, não é (logicamente) possível refutar um enunciado via submissão de suas conseqüências empíricas a testes. Duhem pôs uma espada sobre o ideal racionalista de boa ciência. Popper e Lakatos tentaram, de alguma forma, afastá-la. Quine soltou-lhe as amarras.

Com este ideal fora do caminho, o que nos resta? O pragmatismo, responde Quine. A cada homem, ele diz, é dada uma herança científica e uma carga contínua de estimulação sensorial. Cabe-lhe ajustar uma coisa à outra, e as considerações que o guiam nessa empreitada são, quando racionais, de ordem estritamente pragmática (Quine, 1953, p. 46). Mas, se é assim, então não se pode vetar, $a$ priori, o ato de submeter enunciados a testes via dedução de suas conseqüências empíricas. Tudo o que se pode fazer a respeito é advertir que recorremos a tal expediente por uma mera questão de conveniência, isto é, apenas como um meio eficiente de "prever a experiência futura à luz da experiência passada" (Idem, p. 44). Não devemos nos esquecer, Quine diria, que há maneiras alternativas de conectar o passado ao futuro e que, desde que uma determinada maneira se mostre eficiente na sua esfera específica de atuação, ela vale tanto quanto qualquer outra.

Em seu célebre Humano, demasiado bumano, seção 111, Nietzsche nos fala de um tempo 
em que não havia qualquer noção de causalidade natural. Quando se remava, não era o remo que movia o barco; remar era apenas uma cerimônia mágica, pela qual se forçava um demônio a mover o barco. Se as fontes secavam de repente, pensava-se primeiro em demônios subterrâneos e suas maldades. Quine tem razão: há mesmo maneiras alternativas de conectar o passado ao futuro. A postulação da existência de demônios é uma delas. A postulação de causalidade natural é outra. Não há, Quine diz, descontinuidade entre elas. A única diferença está no grau em que cada uma favorece nossa maneira de lidar com a experiência sensorial imediata (Idem, p. 45). Ao postular tal continuidade, Quine acabou por conduzir, ainda que involuntariamente, a advertência de Duhem a uma espécie de vale-tudo. Se não há descontinuidade entre demônios e causalidade natural; se ambos seriam, como o próprio Quine sugere em seu clássico artigo "Dois dogmas do empirismo", "mitos" de uma mesma espécie, dos quais nos servimos para lidar com nossas experiências sensoriais, e se tudo o que temos a demandar desses "mitos" é que se mostrem eficientes nas circunstâncias particulares em que são mobilizados, então qualquer um deles, desde que bem ajustado a um bloco monolítico de enunciados, e que se mostre útil a um conjunto previamente delimitado de propósitos, deve valer.

Cabe, entretanto, alertar que este vale-tudo não se confunde com o amplamente conhecido vale-tudo de Feyerabend. Apesar de se auto-proclamar "contra o método", Feyerabend sempre se houve com a questão metodológica sem imaginar que ela tivesse de ser subordinada a alguma análise de caráter naturalista. Apesar de sua retórica irracionalista, a preocupação em saber o que é uma boa ciência e como ela é possível é central em seu pensamento. Neste, a resposta para essas perguntas não aparece como um subproduto da resposta para a pergunta: como se adquire conhecimento? Assim, se Feyerabend não considerasse a ciência de Galileu um modelo de boa ciência, ele não teria por que se empenhar em mostrar quão importante foram para o avanço da ciência moderna os esforços, muitas vezes de caráter maquiavélico, deste notável físico e astrônomo italiano para con- vencer os teólogos aristotélicos da validade do sistema copernicano. Diferentemente de Quine, Feyerabend está explícita e profundamente empenhado em saber o que torna uma teoria intrinsecamente digna de interesse. Seu controvertido livro Contra o método quer mostrar que Popper, e os racionalistas de um modo geral, não foram capazes de oferecer uma boa resposta, e não que essa indagação não seja fundamental. Se assim não o fosse, ele não teria por que dizer, como o fez, que "não há uma única teoria digna de interesse que esteja em harmonia com todos os fatos conhecidos que se situam em seu domínio" (Feyerabend, 1977, p. 41). Talvez a essência do naturalismo de Quine, se assim posso me expressar, esteja em dizer exatamente o oposto: toda e qualquer teoria é digna de interesse desde que esteja em perfeita harmonia com todos os fatos conhecidos que se situam em seu domínio. Ou, melhor dizendo: uma teoria só é uma teoria na medida em que consegue se manter em harmonia com todos os fatos conhecidos do seu domínio.

Nos marcos do naturalismo holista de Quine, entretanto, manter-se em harmonia com todos os fatos conhecidos não é uma meta difícil de ser alcançada. As considerações anteriores sobre o modo pelo qual algo como o espetáculo de um pardal agitando as asas pode conduzir a um enunciado como "há transformação de energia nesse local" torna isto claro. Vimos que este último só pode estar conectado a um enunciado como "eis um pardal agitando as asas" se ambos estiverem conectados a todo um conjunto de outros enunciados de graus variados de afastamento em relação ao estímulo original. Os dois enunciados em consideração, e todos os outros, articulam-se assim em um único bloco. O significado de cada um dos enunciados resulta, nessa perspectiva, de sua articulação com todos os outros, e este vasto conjunto de enunciados interconectados exibe um caráter de "campo de forças", que só mantém contato com a experiência sensorial em sua periferia (Quine, 1953 , p. 42). Assim, no exemplo dado anteriormente, o enunciado "A Terra é redonda" ocupa uma posição mais central no "campo". Ele está bastante afastado da experiência sensorial imediata. O enunciado que descreve o que observamos 
quando um navio desaparece na linha do horizonte ocupa a posição mais periférica. Entre um e outro, é possível conceber a existência de muitos outros enunciados, não explicitados, uns mais próximos do centro (os anteriormente mencionados $E_{2}$ e $E_{3}$ ), outros da periferia (o enunciado $E_{1}$ ), conectados entre si e aos dois enunciados em consideração. Se acontecer de a experiência sensorial contrariar um enunciado situado na periferia desse "campo de forças", este último não se verá em dificuldade. Nesse caso, os outros enunciados se redistribuem dentro do campo, isto é, deslocam-se para posições mais centrais ou mais periféricas, de forma a manter o sistema, como um todo, à salvo da experiência sensorial que contrariou o enunciado periférico. Nessa perspectiva, ao contrário do que dizem os livros-textos de metodologia, teorias não se sustentam porque se mostram capazes de resistir a testes cruciais - mesmo porque, agora, teorias sequer podem se prestar a testes cruciais -, mas porque encerram redes de enunciados capazes de se proteger mutuamente sempre que alguma conseqüência empírica de algum desses enunciados é contrariada pela experiência. Daí a impossibilidade, a priori, de uma teoria científica em desarmonia com qualquer fato conhecido de seu domínio.

Estamos, então, diante de uma crítica radical ao ideal racionalista de boa ciência. Conforme vimos, este último veria a sociologia que Durkheim oferece em O suicídio como um inequívoco exemplo de boa ciência. Durkheim procurou mostrar, via submissão de teorias em competição a testes cruciais, isto é, via derivação de uma conseqüência empírica de uma das teorias, cuja negação é implicada pelas demais, que: 1) o suicídio no exército é da mesma natureza que o suicídio em sociedades ditas primitivas, 2) o índice comparativamente baixo de suicídio entre os católicos é da mesma natureza que o índice comparativamente baixo de suicídio entre os judeus e, 3) em ambos os casos, pode-se perfeitamente prescindir da psicologia porque a explicação só pode ser encontrada em um exame da natureza dos laços sociais. Se isso não é um exemplo de boa ciência, diria o ideal racionalista, o que mais poderia ser? O naturalismo holista de Quine, entretanto, não veria ra- zão para tanto entusiasmo. Ele argumentaria que os enunciados que Durkheim presumivelmente refutou podem ser facilmente reabilitados desde que outros enunciados venham em seu socorro. Relembremos, por exemplo, a tese de Durkheim de que a taxa comparativamente elevada de suicídio entre os voluntários requer uma explicação sociológica e exclui a possibilidade de qualquer explicação psicológica para o suicídio no exército. Podese, contra isto, argumentar que os voluntários se matam mais porque, antes de entrar para o exército, alimentam expectativas sobre a vida militar e estas se frustram amplamente. A psicologia estaria, assim, reabilitada. Se esse tipo de exercício for generalizado, algo que pode facilmente ser feito, não restaria pedra sobre pedra do argumento sociológico a respeito de mortes voluntárias. Isso significaria que O suicídio é um irremediável fracasso? Bom pragmatista que é, Quine responderia que não. Responderia que para entender a real contribuição de Durkheim é necessário entender o que ele efetivamente fez. E, de um ponto de vista pragmatista, o que Durkheim efetivamente fez, ao supor haver contribuído para o avanço do conhecimento científico via falseamento de teorias psicológicas incapazes de perceber que a explicação para o comportamento humano reside na natureza dos laços sociais, foi mascarar o fato de que "natureza dos laços sociais" é, tanto quanto o aparato conceitual psicológico a que esta concepção se contrapõe, um dos possíveis "mitos" a que podemos recorrer para estabelecer uma conexão entre nossas experiências passadas e futuras. Se a sociologia de Durkheim pode, de todo, ser considerada uma boa ciência, é somente por razões dessa natureza, ou seja, é somente por ter produzido um ou mais "mitos" potencialmente úteis, e não pelas razões mencionadas nos livros-textos de metodologia científica.

\section{$O$ ideal de boa ciência chega ao fundo do poço}

Apesar de implicar tal crítica contundente aos livros-textos de metodologia, essa versão do naturalismo deixa ainda alguma margem para a 
preocupação com a questão metodológica. Quine questionou a pertinência de uma reflexão metodológica de caráter apriorístico, e não de qualquer reflexão metodológica concebível. Houve, entretanto, quem desse esse passo adicional, conduzindo a abordagem naturalista a um verdadeiro manifesto antimetodológico. Subordinar a reflexão metodológica a uma análise naturalística do processo de aquisição de conhecimento pareceu, a alguns, pouco. Melhor mesmo, diriam, seria acabar logo com esta saga do ideal de boa ciência, dissolvendo-o em uma sociopsicologia do conhecimento. Refiro-me, agora, àqueles que, por falta de melhor nome, chamarei de behavioristas wittgensteinianos. Embora seja clara a influência que receberam de Wittgenstein e de Kuhn, eles são, de fato, herdeiros diretos do empirismo de Hume. Eu reconstruiria idealmente a posição antimetodológica desses sociólogos pós-kuhnianos nos seguintes termos: todas as tentativas de mostrar o que é uma boa ciência fracassaram. Não há, na verdade, por que insistir nisso. No que concerne à prática científica, todos sabem o que é uma "boa" (agora entre aspas) ciência. Devemos, portanto, deixar a questão metodológica de lado e concentrarmo-nos na atividade científica tal como realmente se dá. Em vez de indagarmos o que é uma boa ciência, devemos indagar como definições de "boa ciência" são estabelecidas, aprendidas e incorporadas à prática científica efetiva.

Para além de uma boa crônica da ciência, a quê pode, entretanto, esta linha de investigação conduzir? David Bloor, o mais importante desses sociólogos, parece ter se dado conta de que essa radicalização do naturalismo não tem interesse algum a menos que possibilite, de alguma forma, atingir o que ele mesmo chamou de "o próprio coração do conhecimento" (Bloor, 1976). Ele pretendeu, então, via uma peculiar combinação da psicologia empirista de Stuart Mill com uma estranhíssima concepção sociológica de objetividade à qual chegou, espantosamente, a partir de Frege, "tocar o próprio coração" do conhecimento matemático. Naturalmente, os ecos do naturalismo de Quine se fizeram presentes: só é possível fazê-lo, argumenta Bloor, investigando o modo como efetivamente este conhecimento é adquirido. Como, afinal, isto se dá?
Como se aprende matemática? Bloor vai buscar a resposta em Stuart Mill: aprende-se matemática tomando-se operações físicas com objetos como um modelo para raciocínios abstratos. Crianças brincam com pedrinhas. Elas as ordenam, agrupam, separam etc. Processos de raciocínio matemático são apenas pálidas sombras de operações físicas dessa natureza. É em razão de nossa experiência anterior em ordenar, agrupar e separar objetos físicos que somos capazes, por exemplo, de entender uma equação como $x(x+2)+1=(x+1)^{2}$. Bloor, então, ancora-se em Stuart Mill para mostrar como uma experiência tão primitiva quanto brincar com pedrinhas pode conduzir a algo tão formidável quanto tal equação.

Há, entretanto, lembra Bloor, uma séria lacuna no raciocínio de Mill, para a qual Frege chamou devidamente a atenção: o caráter objetivo do conhecimento matemático ficou sem explicação. Os números, diz Frege, não estão no mundo material da mesma forma que uma árvore está. De uma árvore podemos dizer que é frondosa, verde etc. De um número não é possível dizer nada disso. Os números tampouco estão na mente, no mesmo sentido em que, por exemplo, um sentimento está. Não há o "meu" dois ou o "seu" "dois". Os números, então, fazem parte de um mundo que não é nem o dos objetos materiais nem o das disposições subjetivas. Fazem, antes, parte daquilo que Frege denominou o mundo da objetividade. Bloor concorda com tudo isso e se pergunta: o que é esta objetividade de que fala Frege? A resposta, ele vai buscar no que faltou a Mill: uma sociologia. O único erro de Mill, segundo Bloor, foi não ter percebido que nem toda maneira de operar com objetos físicos serve de matériaprima para nossos raciocínios matemáticos. Há maneiras "caracteristicamente matemáticas" de operar. "Tocar o coração do conhecimento matemático" seria, então, uma questão de entender o que faz de uma situação na qual certas operações são realizadas uma situação "caracteristicamente matemática". Posto o problema desta forma, a resposta ficou fácil: o que torna uma situação "caracteristicamente matemática" é um conjunto determinado de convenções que organizam, a priori, nossas experiências com objetos. Estas autorizam 
certos padrões de ordenação, agrupamento e separação de pedrinhas e desautorizam outros e, ao fazê-lo, conferem ao conhecimento matemático um caráter institucional. Eis, então, o que é a matemática: uma maneira institucionalizada de se comportar. Uma maneira socialmente sancionada de operar com objetos e de fazer inferências a partir daí. E eis o que lhe confere objetividade: seu caráter institucional. Bloor não precisou da espada de Duhem para aniquilar com a metodologia. Bastou-lhe combinar uma versão particular do empirismo de Hume (expresso na aritmética de Mill) com uma versão sociológica, bem ao estilo de Durkheim, do apriorismo kantiano.

\section{A mola no fundo do poço}

Entretanto, nem tudo está perdido. Dizem que existe uma mola no fundo do poço. Para tornar a sua sociologia do conhecimento apta a atingir "o próprio coração do conhecimento", Bloor se viu forçado a jogar qualquer ideal concebível de boa ciência no fundo do poço. Mas, como que por um ato da Providência, ele jogou a mola também: a concepção de objetividade de Frege. É verdade que, ao revestir essa concepção de um caráter de convenção social, ele a desfigurou. Ele distendeu a mola antes de jogá-la no poço. Mas, para isto há remédio. A mola pode ser reparada e, mais do que isso, tornada ainda mais potente.

Para reparar a mola é necessário mostrar como ela foi danificada. Vejamos, então, como Bloor o fez, isto é, como ele desfigurou o pensamento de Frege. Este último, conforme vimos, fala-nos de um mundo que não é físico nem mental, real mas não atual, cujos habitantes são, por exemplo, a linha do equador, o eixo da terra, o centro de massa do sistema solar e os números. Bloor seguiu Frege até aí. Em seguida, entretanto, converteu-o em um sociólogo durkheimiano do conhecimento avant la lettre. Bloor deteve-se no exemplo da linha do equador. Esta linha imaginária, argumentou, é, tanto quanto uma fronteira territorial, uma convenção social. Não, evidentemente, uma convenção qualquer, mas uma que se impõe de forma irresistível. Daí, concluiu: o que mais pode ser a objetividade senão essa tenacidade com que as convenções sociais se impõem a nós? Pobre Frege! Em que naturalista medíocre Bloor o transformou! Não lhe ocorreu que não foi por acaso que Frege mencionou a linha do equador e não o meridiano de Greenwich. Este último é, de fato, uma convenção, no sentido de Bloor. O meridiano passa por Londres, mas não precisaria passar. Nada, a não ser nossas próprias conveniências, nos obriga a mantê-lo ali. O equador, ao contrário, é uma linha imaginária que corta uma postulada figura geométrica pela metade. Para mudá-lo de lugar, teríamos que esticar ou achatar, ainda mais, um dos pólos do planeta. E, mesmo que isto fosse possível, uma nova linha imaginária, que poderíamos continuar ou não chamando de equador, permaneceria cortando uma figura geométrica pela metade. O conceito de metade, a propósito, é mais um habitante do mundo da objetividade de Frege. Comparar a linha do equador com uma fronteira territorial é, então, um nítido despropósito. Como a atribuição de um caráter de convenção social ao conhecimento objetivo de Frege depende de despropósitos dessa natureza, podemos considerar sem efeito o uso que Bloor faz de Frege. Está, assim, restaurada a mola que Bloor distendeu. Vejamos, agora, como o ideal de boa ciência pode se apoiar nela para sair do poço a que foi gradativamente conduzido.

Frege não postulou este terceiro mundo do conhecimento objetivo para falar do equador ou de números, mas, sim, de nada menos que a própria lógica. Desde Aristóteles esta era concebida como o conjunto de regras que governam o pensamento. Frege rompe com isso radicalmente. A lógica é objetiva: não se refere às leis do pensamento, ou, mesmo, nada tem a ver com pensamento. Relações lógicas independem do pensamento humano. Nós, humanos, podemos conhecê-las, aprendê-las, deixar de notá-las, compreendê-las bem ou mal, tanto quanto podemos conhecer, aprender, não notar ou compreender bem ou mal todo um conjunto de outras coisas que existem independentemente de nós. Nesse sentido, proposições lógicas são verdades objetivas. Podemos apreendê-las ou deixar de apreendê-las, mas sua existência nada tem a ver com qualquer característica do pensamento huma- 
no (Magee, 1998, pp. 194-195). Popper (1972) encampou essa concepção e levou-a adiante. Se a lógica é objetiva, teorias também o são: encerram, além de uma heurística objetiva, conforme já vimos, um conjunto de pressupostos (teóricos e metafísicos) objetivos, problemas objetivos e implicações objetivas. Esses pressupostos, problemas e implicações objetivas constituem, por sua vez, situações objetivas que encerram novos problemas objetivos, os quais, se descobertos e tentativamente solucionados, conduzem a novas teorias objetivas que encerram novos problemas, novas implicações objetivas etc.

Quero sugerir que a chave para o resgate de um ideal de boa ciência está nessa noção fregiana-popperiana de implicações objetivas. Afirmar que uma teoria tem implicações objetivas é afirmar que ela é compatível ou incompatível com outras, que pode abranger teorias mais restritas ou ser um caso limite de uma teoria mais abrangente, que objetivamente constitui, ou não constitui, uma ruptura importante com um estado objetivo de conhecimento existente, que, por sua vez, encerra um arcabouço conceitual objetivo, quer de natureza teórica, quer de natureza metateórica, dentro do qual todo um conjunto de teorias formuladas posteriormente vem objetivamente a se mover, entre muitas outras coisas. Essas considerações abrem um campo formidável de investigações: averiguar se, e em que sentido, uma determinada teoria representa uma ruptura com um estado objetivo de conhecimento existente, se sua contribuição objetiva para um estado objetivo de conhecimento reside em seu sucesso experimental ou no fato de encerrar, objetivamente, uma heurística compatível com certas teorias e incompatível com outras e/ou um arcabouço conceitual dentro do qual outras teorias, formuladas posteriormente, objetivamente se movem etc. O crucial de meu argumento é o de que não é possível se haver com indagações dessa natureza sem que um ideal de boa ciência, imune à espada de Duhem, esteja objetivamente subentendido. Posto de outra forma, a própria existência desse campo objetivo de investigação pressupõe a existência objetiva de tal ideal.

\section{O salto para fora do poço: a saga continua...}

Se é assim, e se estamos no mundo fregiano da objetividade, então tudo o que temos de descobrir é se existe objetivamente alguma área de investigação que não possa existir como tal se não se houver permanentemente com indagações como aquelas levantadas acima. Em outras palavras, se existe alguma área de investigação que para se manter como tal precisa permanentemente se perguntar se uma teoria representa ou não alguma descontinuidade com um dado estado objetivo de conhecimento, se a importância de uma teoria reside em seu arcabouço conceitual ou em seu sucesso experimental etc. Receio que esta área de investigação exista e seja conhecida pelo nome de história da ciência.

A fim de desenvolver este ponto, peço licença para fazer uma longa citação. Como é a primeira e será a única deste artigo, espero que o leitor releve. Trata-se de um texto do célebre historiador da ciência Bernard Cohen, publicado originalmente em 1956. Interessa-me mostrar quão vulnerável fica a historia da ciência à espada de Duhem e, por extensão, à capitulação ao naturalismo na ausência de um bom ideal de boa ciência. Passemos, então, a palavra a Cohen:

Um dos mais importantes assuntos de pesquisa na História da Ciência, nós o encontramos na relação entre a "Revolução Científica" do século XVII e a imaginação humana. Um dos maiores momentos na evolução da ciência, um momento, realmente, com que nada se compara na evolução de todo o pensamento científico, ocorreu em 1609, quando Galileu apontou seu telescópio para os céus. Até então, travavam-se discussões sobre a natureza e movimento das estrelas e outros corpos celestes, além de especulações sobre a natureza dos sistemas cósmicos, caráter e características desses corpos. Quando Copérnico afirmou que a Terra era apenas outro planeta, suas palavras pouco significavam porque as observações a olho nu não revelavam qualquer semelhança entre a Terra e as estrelas. Dizer que algumas estrelas, chamadas de planetas, moviam-se nos céus em relação umas às outras, algumas vezes para frente e outras para trás, pouco justifica- 
va a opinião de que eram semelhantes à Terra. A maioria das pessoas considerava as estrelas como uma espécie de corpos perfeitos, imutáveis, puros, em contraste com a Terra, onde havia decomposição, nascimento, vida, morte e transformações de todo os tipos. As características físicas da Terra, por conseguinte, podiam explicar sua posição única como centro do universo, o lar conveniente para o homem que era, em si mesmo, impuro, pecador e corrompido. Ao assestar para o céu o telescópio, Galileu viu pela primeira vez como era realmente o firmamento. Descobriu que a Lua possuía montanhas e vales e que parecia uma Terra em miniatura, embora fosse uma Terra morta. A Terra, descobriu ele, refletia a luz do Sol e iluminava a Lua, o que comprovava que a Terra brilhava como os demais planetas e teria o mesmo aspecto para um observador que se encontrasse em Marte ou Vênus. Este último mostrava fases como a Lua, o que presumivelmente acontecia também à Terra e aos demais planetas. Verificou ele ainda que Júpiter possuía quatro luas, dessa maneira eliminando mais um dos aspectos de singularidade da Terra, até então considerada o único corpo celeste que possuía satélite.

As descobertas de Galileu sugeriram que as opiniões de Copérnico sobre o universo podiam ser consideradas como algo mais do que simples abstração matemática, mais do que um expediente para computar posições futuras dos planetas e da Lua. Não era mais absurdo julgar a Terra um planeta, uma vez que a Terra e os planetas possuíam tantas características comuns, como revelava o telescópio. Evidentemente, quando Galileu publicou um relato de algumas dessas descobertas no Mensageiro Sideral, de 1610, o efeito foi explosivo. Daí em diante, cientistas e teólogos eram forçados a considerar as conseqüências da residência do homem sobre uma Terra que fora posta em movimento e que estava relegada a uma posição sem maior importância no sistema solar e não mais era o centro do universo. Ao mesmo tempo, poetas, teatrólogos e filósofos encontravam campo para a imaginação nas possibilidades de um vasto e até então desconhecido universo, finalmente revelado ao homem. As estrelas, os planetas, a Via Láctea, o próprio sol, e as nebulosas, presumivelmente, circulavam no espaço desde o dia em que Deus havia criado o mundo, mas o homem jamais os conheceu até o dia em que Galileu apontou seu telescópio para os céus (Cohen, 1963, pp. 166-167).
O exacerbado otimismo epistemológico que este texto exibe é tudo o que o naturalismo sociológico peculiar a Bloor e aos sociólogos pós-kuhnianos de um modo geral precisa para se regozijar. Para Cohen, acreditar que a Terra é apenas mais um planeta ou que a lua possui montanhas e vales é uma mera questão de substituir o olho nu por um telescópio. Para ele, crer é uma questão de saber ver. Contra esse exacerbado otimismo, deve ser suficiente lembrar que, de um modo geral, só acreditamos no que vemos quando o que vemos não contradiz nossas expectativas sobre o modo como o mundo é. Como as descobertas de Galileu a que Cohen faz menção contradiziam as tenazes expectativas dos teólogos e astrônomos aristotélicos, é uma ingenuidade supor que a balança penderia tão facilmente para o lado dessas descobertas. Ao incorrer neste deslize, Cohen tornou-se extremamente vulnerável à espada de Duhem; ele tornou-se uma presa fácil de objeções do tipo: o quê, no século XVII, poderia garantir que as "montanhas e vales na lua", ou as "luas de Júpiter", não eram apenas uma ilusão de óptica a que o uso de tão estranho instrumento, o telescópio, poderia ter conduzido? Por que, nessa época, dar crédito a um instrumento óptico cujo funcionamento mal se conhecia se ele contrariava uma sabedoria já consagrada por uma tradição milenar? Toda uma historiografia da ciência, cuja obra paradigmática parece ser o livro Leviathan and the Air-Pump (Shapin e Schaffer, 1985), desenvolveu-se nos últimos anos em torno de questões dessa natureza, isto é, em torno da tese trivialmente correta de que crer não é uma mera questão de ver; de que a verdade não traz uma marca na testa. Esta historiografia da ciência é sobretudo um legado natural da capitulação do ideal de boa ciência, e deve ser muito grata aos historiadores da ciência que se permitiram exibir o mesmo imoderado otimismo epistemológico que Cohen exibiu.

Esse imoderado otimismo pode, entretanto, ser evitado desde que o carro-chefe da história da ciência não traia, como no caso de Cohen, um ideal de boa ciência tão nitidamente vulnerável à espada de Duhem. Foi somente por subscrever irrefletidamente um ideal desta natureza que Cohen pôde 
sustentar que a marca da revolução científica foi o conjunto de observações contra-intuitivas obtidas através do telescópio de Galileu.

Mas, afirmar que Cohen errou porque o ideal de boa ciência que dá sustentação a seu argumento não é bom é admitir que esse ideal deve ser substituído por um melhor e que um bom ideal de boa ciência é imprescindível para a condução de qualquer investigação na história da ciência. Há, felizmente, historiadores da ciência que se deram plenamente conta desse fato e jamais ousaram fazer qualquer investigação histórica sem que uma reflexão metodológica não ocupasse a posição central. Alexandre Koyré é o caso exemplar. Sua história da ciência é informada por um ideal de boa ciência que eu, trazendo-o para o mundo da objetividade de Frege, sintetizaria na seguinte fórmula: boa ciência é a que tem algum impacto objetivo tanto sobre um estado objetivo de conhecimento anterior como sobre um estado objetivo de conhecimento posterior. Os impactos objetivos mais evidentes sobre um estado de conhecimento anterior são o de permitir a continuidade deste estado de conhecimento ou o de romper com ele. Mas há outros. Veja-se o caso da genética mendeliana, cujo impacto objetivo retrospectivo está em ter viabilizado a continuidade da teoria da evolução por seleção natural ao fundir-se com ela na chamada síntese evolutiva. Quanto aos impactos prospectivos, estes ocorrem na medida em que teorias encerram situações objetivas para a emergência de novos problemas e/ou de novos arcabouços conceituais que constituam referenciais objetivos dentro dos quais outras teorias possam objetivamente se mover. No que concerne a este ponto, o melhor exemplo que tenho em mente é o da teoria da fagocitose, de 1883, de Metchnikoff (Cf. Tauber, 1991). A situação objetiva que esta teoria encerra é composta pela premissa metafísica de um organismo intrinsecamente desarmônico, mas em permanente luta pela harmonia, e pela tese metateórica, que repousa sobre esta premissa, de que nosso sistema imunológico não deve sua existência à luta contra um agente infeccioso, mas à coexistência, em qualquer estágio do desenvolvimento ontogênico, de estruturas de diferentes origens filogenéticas, requerendo, portanto, um mecanis- mo ativo que viabilize esta coexistência. Uma vez que a fagocitose (a ingestão de corpos sólidos por células mesodérmicas amebóides tais como os leucócitos) se caracteriza por ser justamente este mecanismo, ela se torna o elemento-chave da imunidade. Desta situação objetiva emergiu tanto o conceito que ancora objetivamente toda a imunologia moderna, a saber, o de um hospedeiro ativamente responsivo, como o problema em torno do qual esta objetivamente se move, a saber: como um organismo distingue o que lhe é próprio do que lhe é estranho.

Impõe-se, neste ponto, um contraste com Kuhn. As considerações acima sobre o caráter de boa ciência da teoria da fagocitose podem parecer uma rendição à tese kuhniana de que boa ciência é aquela que dispõe de um paradigma amplamente aceito no interior do qual uma "ciência normal" pode se desenvolver. Devo, entretanto, dizer que não é este o argumento que quero fazer ao dizer que a teoria da fagocitose fornece um arcabouço conceitual imprescindível para as teorias modernas de imunidade. Em primeiro lugar, porque a concepção kuhniana inscreve-se no behaviorismo wittgensteiniano a que anteriormente fiz menção. Para Kuhn, boa ciência é, ao fim e ao cabo, qualquer uma que se mostre capaz de proporcionar segurança e conforto para seus praticantes. A teoria da fagocitose, pelo que sei, jamais proporcionou segurança ou conforto aos imunologistas. Ao contrário, muitos viam nela um traço de misticismo. De acordo com os padrões kuhnianos, ela não mereceria muita atenção. Em contraposição, meu argumento é o de que uma teoria não precisa desfrutar de um caráter paradigmático, no sentido kuhniano, para ter um papel fundamental na história de uma ciência. A teoria da fagocitose ilustra esse fato exemplarmente bem. Além de seu acentuado teor metafísico, ela era de difícil operacionalização, e tudo isso a impediu de ser vista como um modelo de ciência a ser seguido. Nem por isso, entretanto, ela deixou de ter um impacto fundamental, que não se mede pela contagem de citações. Seu impacto é objetivo no sentido fregiano-popperiano: há um "antes" e um "depois" dela, mesmo que os imunologistas jamais tenham se dado conta disso. 
Uma vez exposta a concepção de boa ciência de Koyré, posso mostrar como ela constitui o carro-chefe de sua investigação histórica. No mesmo ano em que Cohen publicou o texto que reproduzi anteriormente, Koyré publicou um artigo intitulado: "As origens da ciência moderna: uma nova interpretação" (Koyré, 1991). Ao contrário de Cohen, contudo, que irrefletidamente assumiu um ideal de boa ciência vulnerável à espada de Duhem para discorrer sobre as origens da ciência moderna, Koyré subordinou sua interpretação sobre este mesmo processo a uma prévia reflexão metodológica. Ele se perguntou o que faz da ciência de Galileu uma boa ciência. A resposta, ele foi buscar nos impactos objetivos, retrospectivos e prospectivos, desta ciência. O impacto retrospectivo mais importante foi a destruição do Universo fechado e hierarquizado da física escolástica via substituição do espaço concreto de Aristóteles pelo espaço abstrato da geometria euclidiana. O prospectivo está em ter preparado o terreno para o desenvolvimento do conceito de inércia ao romper com a concepção aristotélica de que o repouso é o estado natural e o movimento uma alteração forçada deste estado. Galileu não permitiu que o repouso desfrutasse do privilégio ontológico que a física escolástica lhe concedera. Sem essa dupla subversão, argumenta Koyré, um telescópio nada pode. É ela, e não o telescópio a que tão entusiasticamente alude Cohen, que está na base da transição do sistema ptolomaico para o copernicano. Um bom ideal de boa ciência permitiu, então, a Koyré nos mostrar a verdadeira natureza da revolução científica: tratou-se, sobretudo, de uma revolução conceitual.

Diante do exposto, o contraste com a capitulação naturalista é inevitável. Esta, conforme vimos, consiste em subordinar a questão metodológica a uma análise do processo de aquisição do conhecimento. Para proceder a tal análise, o aprendizado de uma língua materna, ou de uma língua estrangeira, é tomado como modelo. Um efeito imediato dessa maneira de proceder é excluir, de antemão, a possibilidade da existência de descontinuidades no conhecimento. Afinal, o aprendizado de uma língua é um processo cumulativo, contínuo. Tomemos, como exemplo, o aprendizado do inglês. Não foi preciso esperar por Quine ou Wittgenstein para que soubéssemos que uma sentença como "this is a table" não esgota as possibilidades de traduzir a sentença "isto é uma mesa". Entretanto, o naturalismo holista de Quine, ele próprio uma variante da tese wittgensteiniana de que o significado das palavras reside em seu uso efetivo, convida-nos a admitir uma possibilidade mais radical: a de traduzir uma sentença como "isto é uma mesa" para o inglês sem que seja necessário fazer uso de termos como "this", "is", " $a$ " e "table". Mais do que isto, convida-nos a conceber traduções de "this is a table" que sejam incompatíveis com "isto é uma mesa". Não tenho qualquer dificuldade em concordar com essas idéias. Afinal, não é difícil conceber situações do uso cotidiano das palavras em que "sim" significa "não", ou vice-versa. Todavia, nada disso implica descontinuidade. Esta só se verificaria se fosse possível conceber uma tradução para "this is a table" que tornasse uma tradução como "isto é uma mesa" objetivamente inconcebível. Assim, a descontinuidade no aprendizado de uma língua é também impossível. Receio que a realização mais espetacular da capitulação naturalista tenha sido a de estender, de antemão, essa impossibilidade para o conhecimento. Em outras palavras, é ter tornado o conhecimento necessariamente contínuo e cumulativo. Isso excluiria a possibilidade de rupturas como a que Cohen descreve. De acordo com esse raciocínio, a verdadeira razão para refrear o entusiasmo de Cohen não está no imoderado otimismo epistemológico que este traz embutido, mas no fato de encerrar uma visão descontínua do conhecimento.

Koyré subverte tudo isso ao subordinar todo um campo de investigação à reflexão metodológica. Deste campo faz parte averiguar aquilo que o naturalismo próbe de antemão: se há, e em que sentido, descontinuidades no conhecimento. Se Koyré discorda de Cohen, não é porque este último permitiu que entre Aristóteles e Galileu houvesse uma descontinuidade, mas, sim, em razão de faltar a Cohen um ideal de boa ciência bom o suficiente para viabilizar a compreensão da natureza dessa descontinuidade. Há, entretanto, um importante ponto em comum entre Quine e Koyré: ambos rejeitam, enfaticamente, a emissão de 
juízos baseados em cânones metodológicos estabelecidos a priori. Quine, conforme vimos, não partilharia do entusiasmo que um livro-texto de metodologia científica alimentaria por discussões como a de Durkheim sobre o suicídio no exército ou sobre as taxas comparativamente baixas de suicídios entre católicos e judeus. Ele veria esse tipo de discussão como uma presa fácil para a espada de Duhem. Koyré, certamente, partilharia desse desencanto. Mas não teria, a meu ver com razão, por que creditá-lo à vulnerabilidade dos argumentos de Durkheim às advertências de Duhem. O problema está em outro lugar. Receio que a sociologia contida em O suicídio seja um claro exemplo de má ciência que passa por boa ciência quando submetida aos cânones metodológicos de boa ciência. Não que eu me oponha a procedimentos como, por exemplo, corroborar um enunciado e, ao mesmo tempo, refutar vários enunciados alternativos por meio de um simples expediente como derivar do primeiro uma conseqüência empírica cuja negação é demandada por todos os outros. Porém, se tal procedimento é tão louvável, e tão ubíquo em O suicídio, então por que considerar a sociologia contida nesse livro uma má ciência? A resposta está em três perguntas: Que problema objetivo emergiu a partir desta sociologia? O que ela objetivamente destruiu? O que ela objetivamente pôs no lugar? Para dar uma idéia do que estou perguntando, vou mostrar quais seriam as respostas se a pergunta se referisse à teoria da fagocitose de Metchnikoff. O que ela objetivamente destruiu? A concepção passiva do processo de imunidade peculiar a toda a imunologia do século XIX, incluindo-se a de Pasteur. O que ela objetivamente pôs no lugar? Uma concepção ativa do processo de imunidade, sobre a qual se moveu objetivamente toda a imunologia do século XX. Que problema objetivo emergiu a partir dela? O de como o organismo distingue o que lhe é próprio do que lhe é estranho. É possível dar respostas remotamente análogas a estas se perguntarmos pelo impacto objetivo, quer retrospectivo quer prospectivo, da sociologia de $O$ suicídio? Acredito que $A$ divisão do trabalho social e, para não dizer que não falei de Max Weber, A ética protestante e o espírito do capitalismo resistiriam com folga a um teste des- sa natureza. Quanto a O suicídio, tenho sérias dúvidas. Posso, evidentemente, estar enganado sobre esse assunto. Mas não é isso o que importa. A lição que quero tirar dái é outra. Vimos que não pode haver história da ciência sem um ideal de boa ciência - o que pode haver, e infelizmente tem havido, é história da ciência que, ao desdenhar a reflexão metodológica, deixa-se guiar, irrefletidamente, por um ideal empirista ou pragmatista de boa ciência. Mas, se não há como escapar de uma reflexão metodológica para reconstruir a história de alguma ciência, por que não utilizar essa reflexão para emitir juízos sobre a qualidade de outras? Por que não usar um juízo sobre, digamos, a teoria da fagocitose, como um modelo para emitir juízo sobre a sociologia contida em O suicídio? Trata-se, certamente, de uma operação de alto risco. Mas receio que não tenhamos escolha. Ou corremos o risco de nos equivocar em nossos juízos, um risco que pode ser atenuado se contarmos com a inestimável ajuda do mundo da objetividade de Frege, ou nos condenamos a subscrever, de forma acrítica, juízos já estabelecidos. É verdade que a segunda alternativa tem prevalecido, mas não precisamos daí concluir que ela tenha de continuar a prevalecer, isto é, que a saga do ideal de boa ciência já tenha conhecido o seu fim.

\section{BIBLIOGRAFIA}

BLOOR, David. (1976), Knowledge and social imagery. Chicago, The University of Chicago Press.

COHEN, I. Bernard. (1963), "A imaginação da natureza", in L. White Jr. (org.), As fronteiras do conbecimento: um estudo do bomem, Rio de Janeiro, Fundo de Cultura.

FEYERABEND, Paul. (1977), Contra o método. Belo Horizonte, Livraria Francisco Alves Editora.

KOYRÉ, Alexandre. (1991), Estudos de bistória do pensamento científico. 2 ed. Rio de Janeiro, Forense. 
LAKATOS, Imre. (1970), "Falsification and the methodology of scientific research programmes", in I. Lakatos e A. Musgrave (orgs.), Criticism and the growth of knowledge, Cambridge, Cambridge University Press.

MAGEE, Bryan. (1998), The story of philosophy. Londres, Dorling Kindersley.

POPPER, Karl R. (1972), Objective knowledge. Londres, Oxford University Press. (1999), A lógica da pesquisa científica. 9 ed. São Paulo, Cultrix.

QUINE, Willard O. (1953), From a logical point of view. Cambridge, Mass., Harvard University Press.

SHAPIN, Steven \& SCHAFFER, Simon. (1985), Leviathan and the Air-Pump. Princeton, Oxford University Press.

STINCHCOMBE, Arthur L. (1968), Constructing social theories. Nova York, Brace and World.

TAUBER, Alfred L. (1991), "The immuniological self: a centenary perspective". Perspectives in Biology and Medicine, 35 (1): 74-86. 
REVISTA BRASILEIRA DE CIÊNCIAS SOCIAIS - VOL. 19 No. 55

\section{A SAGA DO IDEAL DE BOA CIÊNCIA}

Renan Springer de Freitas

\section{Palavras-chave}

Metodologia; História da ciência; Naturalismo; Sociologia do conhecimento; Epistemologia.

O colapso do ideal baconiano de boa ciência, o subseqüente insucesso dos empiristas do Círculo de Viena em estabelecer um ideal substituto e a pertinência da crítica de Pierre Duhem ao ideal racionalista levaram a reflexão sobre o que é boa ciência a subordinar-se a uma análise naturalística do processo de aquisição de conhecimento ou, simplesmente, a dissolver-se em uma sociopsicologia do conhecimento. Sugere-se que nenhuma dessas formas de capitulação seja necessária. A reflexão sobre o que é boa ciência, ou, para usar um termo mais familiar, a metodologia, pode reencontrar seu caminho se assumir a posição que, por assim dizer, lhe é de direito: a de carro-chefe da história da ciência. Argumentase que a metodologia foi conduzida ao fundo de um poço do qual não há mais como sair a não ser dando um salto vertiginoso, e discute-se a viabilidade deste salto.

\section{THE SAGA OF THE GOOD SCIENCE IDEAL}

Renan Springer de Freitas

\section{Key words}

Methodology; History of science; Naturalism; Sociology of knowledge; Epistemology.

The collapse of the Baconian ideal of good science, the subsequent failure of the empiricists of the Vienna Circle in establishing a substitute ideal, and the pertinence of Pierre Duhem's criticism to the rationalist ideal have led the reflection on what is good science to either submit itself to a naturalistic analysis of the process of knowledge acquisition or, simply, dissolve itself into some kind of socio-psychology of knowledge. The article suggests that none of these forms of capitulation is necessary. A reflection on what good science is, or, to use a more familiar term, methodology, can find its way again by taking the position it has always been entitled to, namely that of the very guide of the history of science. The article both claims that methodology has been led to the deepest part of a well from which it will not be able to leave unless it takes a vertiginous leap, and discusses the viability of this leap.

\section{LA SAGA DE L'IDÉAL DE LA BONNE SCIENCE}

Renan Springer de Freitas

\section{Mots-clés}

Méthodologie; Histoire de la science; Naturalisme; Sociologie du savoir; Epistémologie.

Le collapsus de l'idéal de Bacon à propos de la bonne science et l'insuccès qui s'en suivit en ce qui concerne les empiristes du Cercle de Vienne d'établir un idéal de substitution, ainsi que la pertinence de la critique de Pierre Duhem à l'idéal rationaliste, ont mené à une réflexion à propos de ce qu'est la bonne science et de sa subordination à une analyse naturaliste du processus d'acquisition du savoir ou, tout simplement, à sa dissolution en une socio-psychologie du savoir. Nous suggérons qu'aucune de ces formes de capitulation n'est nécessaire. La réflexion sur ce qu'est la bonne science ou, pour employer un terme plus familier, la méthodologie, peut retrouver son chemin et assumer une position qui, pour ainsi dire, lui revient de droit : celle de chef de file de l'histoire de la science. Nous soutenons que la méthodologie a été lançée au fond d'un puits dont il n'est plus possible d'en sortir, à moins d'un saut vertigineux. Et nous questionnons la viabilité de ce saut. 